\title{
Ocular trauma in school going children- An analytical study
}

\author{
S. Amudhavadivu' ${ }^{1}$, Y. Rogavi ${ }^{2}$, J. Gnanaselvan ${ }^{3 *}$ \\ ${ }^{\mathbf{1}}$ Associate Professor, ${ }^{2}$ Junior Resident, ${ }^{3}$ Professor, Dept. of Ophthalmology, Thanjavur Medical College, Thanjavur, Tamil Nadu, India
}

\section{Article Info}

Received: $19^{\text {th }}$ February, 2019

Accepted: $8^{\text {th }}$ April, 2019

Published Online: $9^{\text {th }}$ September, 2019

Keywords: Accidental fall, Ocular Trauma, Road traffic accidents, School going children, Visual disability.

\begin{abstract}
Introduction: Ocular trauma is one of the major causes of preventable childhood blindness in the world. Ocular injuries lead to visual disability, cosmetic problems and psychosomatic abnormalities.

Aim and Objective: To study the prevalence and characteristics of ocular trauma in school going children.

Materials and Methods: This hospital based analytical study included the school going children presented with ocular trauma at the tertiary eye care hospital. A study proforma was used to obtain various socio-demographic information, detailed history and relevant findings on ocular examination. Descriptive and comparative analyses were performed.

Results: One hundred and twenty patients with ocular injuries in the age group five to eighteen (5-18) were examined. Maximum of Sixty three (63) cases were recorded in the age group of Eleven to Fifteen (11-15) years. $81.6 \%$ of the cases were boys, 35 patients had accidental fall injury, 17 patients had road traffic accidents, and 6 cases had posterior segment involvement. One hundred and six of the patients had closed globe injury; Twenty seven (27) patients had a visual acuity of less than $6 / 60$ at the time of presentation. Twenty one (21) patients had a final visual outcome of $6 / 60$ or less at the end of one year.
\end{abstract}

\section{Introduction}

The eye is a most valuable sense organ that provides a stereoscopic view of our surroundings. Nearly $38 \%$ of the sensory output to the brain is contributed by our eyes. Ocular trauma is more common in children and approximately a quarter of a million of them present with serious ocular trauma, because they are unaware and their tendency to imitate adult behavior without knowing the risks and because of ignorance and natural curiosity. ${ }^{1-4}$ Ocular injuries represent for around Eight to Fourteen Percent ( 8 to $14 \%$ ) of total injuries in children. The blind truth is that most of these injuries are preventable by simple measures. Ocular injuries lead to visual impairment, cosmetic problems and are associated with psychosomatic abnormalities. Ocular trauma is mostly preventable by simple measures, literacy and awareness. Visual loss due to trauma is irreversible and hence prevention of trauma is of paramount importance. . $^{4-8}$

\section{Aim}

The main aim is to identify the causes and clinical spectrum of ocular trauma. We will also find out the possibilities of prevention of visual loss in these school going children.

\section{Materials and Methods}

School going children of five to eighteen years (5 to18) of age who reported to the department of Ophthalmology, Thanjavur Medical College, Thanjavur with presentation of ocular injuries from December 2015 to July 2017 were followed up for this study.

One hundred and twenty (120) children who reported to our department with history of ocular injuries were subjected to this analytical study. Detailed history taking was done. Visual acuity examination, anterior segment, posterior segment examination by means of Slit Lamp, Intra Ocular Pressure measurement, direct ophthalmoscopy and Indirect Ophthalmoscopy was done. Radiological investigation, B mode Ultrasonography and Computed Tomography/ Magnetic resonance Imaging (CT/MRI) were done whenever required. Ocular and orbital injuries having orbital wall fractures, extra ocular muscle and orbital pad of fat herniation or orbital wall fractures can accurately be detected with computed tomographic scan. Intra ocular foreign body can also be located with this. Orbital wall fracture evaluation can also be done with this and saggital view is important in evaluating blow out fractures of the orbital floor. Patients with minor injuries were treated as out patients and those with complications were admitted as inpatients in ward and given treatment accordingly. All patients were initially called up one week after discharge from the hospital for regular check up. Patients were followed up monthly once for a period of one year depending upon the nature of the trauma.

\footnotetext{
*Corresponding Author: J. Gnanaselvan, Professor, Dept. of Ophthalmology, Thanjavur Medical College, Thanjavur, Tamil Nadu, India Email: helengs18@hotmail.com http://doi.org/10.18231/j.ijceo.2019.096
} 


\section{Inclusion Criteria}

School going children, five to eighteen (5-18) years of age, both sex, unilateral or bilateral and any mode of injury has been included in this study.

\section{Exclusion Criteria}

Children less than five $(<5)$ years and more than eighteen (>18) years of age, ocular morbidity if already existing, congenital anomalies will be excluded from our study.

\section{Observation and Results}

Children of eleven to fifteen years of age were more frequently involved in ocular trauma. It was more commonly seen in the age group of Eleven to Fifteen (11$15)$ years $(52.5 \%)$ followed by Three to Ten $(3-10)$ years of age. Boys were more commonly affected $(81.6 \%)$. The most common pattern of injury is accidental fall (29.1\%), followed by stick injury (18.3\%), blunt injury (15.2\%) and Road Traffic Accidents (14.1\%). Among Road Traffic Accidents, Bicycle users (47.1\%) and Pedestrians (35.2\%) were more commonly involved.

Table 1: Frequency of trauma and incidence

\begin{tabular}{|l|c|c|}
\hline Type of trauma & No. of children & $(\%)$ \\
\hline Thorn & 08 & 6.6 \\
\hline Ball & 10 & 8.3 \\
\hline $\begin{array}{l}\text { Road Traffic } \\
\text { Accidents }\end{array}$ & 17 & 14.1 \\
\hline Blunt Injury & 18 & 15 \\
\hline Stick & 22 & 18.3 \\
\hline Accidental Fall & 35 & 29.1 \\
\hline Others & 10 & 8.3 \\
\hline
\end{tabular}

Among the ocular involvement, lid problems were seen in $88.3 \%$ of patients, $80.3 \%$ of children were with problems of conjunctiva, Iris and pupil in $18.1 \%$, Anterior chamber involvement in $14.1 \%$ of children and Orbital wall in $11.6 \%$ of children.

Among the One Hundred and twenty children, 5 were affected with lid tear. 5 were having conjunctival tear. Corneal epithelial defect seen in 11children (9.1\%), 10 children $(8.3 \%)$ had corneal tear. 4 had Scleral tear $(3.3 \%)$, 17 children had anterior chamber involvement. Among these three children had blood in anterior chamber (2.5\%), six children was having cells and flare in the anterior chamber (5\%) and variable anterior chamber depth seen in eight children $(6.6 \%)$ relative afferent pupillary defects seen in eight children(6.6\%).

23 children were having involvement of iris or pupil. Among them iris prolapse was seen in six children (5\%). Traumatic fixed dilatation of the pupil in three $(2.5 \%)$. Two children was having traumatic lens opacification, six children had Berlin's edema of the macula. All the nine children had only problem with the optic nerve. In orbit, Lateral wall fracture was seen in seven cases $(5.8 \%)$, Roof fracture seen in five children (4.1\%). Floor Fracture seen in two children $(1.6 \%) .11 .6 \%$ of children was seen having open globe injuries and $88.4 \%$ children had closed globe injuries.
Table 2: Incidence and nature of trauma

\begin{tabular}{|l|c|l|}
\hline Nature of trauma & No. of children & $(\mathbf{\% )}$ \\
\hline Closed globe & 106 & 88.3 \\
\hline Openglobe & 14 & 11.6 \\
\hline
\end{tabular}

At the time of presentation to our department, Thirty Five (35) children had normal visual acuity and Eighty Five (85) had abnormal visual acuity.

Among these, Twenty Seven (27) children had less than $6 / 60$ visual acuity, of these Eleven (11) had very poor visual acuity of perception of light and no perception of light was seen in two children.

Table 3: Visual acuity at the time of admission

\begin{tabular}{|l|c|c|}
\hline Visual acuity & No. of children & $(\boldsymbol{\%})$ \\
\hline No Perception of Light & 02 & 1.6 \\
\hline Perception of Light Present & 11 & 9.1 \\
\hline Counting Fingers Close to Face & 02 & 1.6 \\
\hline $6 / 60-1 / 60$ & 12 & 10 \\
\hline $6 / 18-6 / 36$ & 15 & 12.5 \\
\hline $6 / 9-6 / 12$ & 43 & 35.8 \\
\hline $6 / 6$ & 35 & 29.1 \\
\hline
\end{tabular}

\section{Final visual outcome at one year}

Normal visual acuity was seen in Seventy Eight (78) children and Forty Two children (42) had abnormal visual acuity. Of these, Twenty One (21) had gross visual acuity defect of less than $6 / 60(<6 / 60)$ and no perception of light was seen in Four (4) children.

Table 4: Final visual acuity

\begin{tabular}{|l|c|c|}
\hline Visual acuity & No. of children & $(\boldsymbol{\%})$ \\
\hline No Perception of Light & 04 & 3.3 \\
\hline Perception of Light Present & 07 & 5.8 \\
\hline Counting fingers close to Face & 01 & 0.8 \\
\hline $6 / 60-1 / 60$ & 09 & 7.5 \\
\hline $6 / 18-6 / 36$ & 03 & 2.5 \\
\hline $6 / 9-6 / 12$ & 18 & 15 \\
\hline $6 / 6$ & 78 & 65 \\
\hline
\end{tabular}

\section{Discussion}

One hundred and twenty (120) school going students of Five to Eighteen (5-18) years of age, presented to our department with history of ocular injury were analyzed.

A wide spectrum of ocular injuries was identified.

Accidental fall with $29.1 \%$ was the most frequently observed mode of trauma followed by stick injuries.

In our study $81.5 \%$ of children were boys and $18.5 \%$ were girls. Most of the injuries were seen in eleven to fifteen (11-15) years of age (52.5\%). Right eye involvement was seen in fifty six (56) children and Left eye was involved in fifty six (56) children. Both eye involvement is seen in $6.6 \%$ of cases. $14 \%$ of ocular trauma were due to Road Traffic accidents. Similar findings were reported in various literatures. ${ }^{4,6,9-12}$

The most common ocular manifestation was lid involvement followed by Conjunctival injuries. 
Lens injuries were seen in 2 children. Orbital injuries were seen in 14 children and Posterior segment involvement in 6 children.

A gross defect in visual acuity (less than $6 / 60$ to No Perception of Light) was seen in $22.5 \%$ of cases at the time of presentation.

Most of the children in our study had closed globe injuries (106) while 14 of the children had open globe injuries.

On admission two (2) children had no perception of light while it increased to four (4) children at time of serial follow up. All the patients who had become blind suffered ocular injuries from Road Traffic Accidents. Of the one hundred and twenty (120) cases, accidental injuries were most common cause of the injury. Thirty five (35) cases were due to $(29.1 \%)$ - accidental fall, followed by stick injury twenty two (22) cases $(18.3 \%)$, ten (10) cases of injury with ball (8.3\%), eighteen (18) cases with injury by hand-blunt injury (15\%), eight (8) cases presented with thorn injury (6.6\%), Road traffic accident cases (14.1\%), remaining were due to other causes like cracker burns, battery burst, burns injury with iron rod $(8.3 \%)$. Similar findings were reported in various literatures. ${ }^{4,-12,13}$

\section{Conclusion}

Our study shows that ocular injuries are one of the leading causes of visual disability in children. Sometimes it may lead to life time handicap in this vulnerable group.

Boys are especially more exposed to ocular injuries when compared to girls because of their attitude and aggressive behavior. Road traffic accidents mostly cause gross visual damage in these young age group of children. Anterior segment involvement is seen in most of the injuries. The final visual acuity in open globe trauma and optic nerve damage had a very poor prognosis in children. The ultimate goal of ocular injuries in school going children is prevention.

The most important aspect of ocular injuries in school going children is prevention. Parents and teachers have a great role in this. They have to be educated in preparing the safe environment for the children. Every time children alone could not be pointed out for their activities. Adequate adult monitoring and proper ocular protection should be emphasized while when handling or playing with sharp instruments like pencils, scissors or sticks. Visual disability can be prevented by timely prevention of accidents, early detection of injuries and with appropriate management.

Ocular injuries in children are more common and it may cause vision threatening complications. Very gross poor visual outcome is more commonly associated with open globe ocular trauma and traumatic optic nerve injuries that are caused by road traffic accidents. The irreparable nature of visual disability associated with this type of ocular trauma should be well explained to the community populations and school going pediatric age group by means of audio-visual aids. Better preventive health aspects to avoid late identification and delay in initiation of treatment must be established in all communities. Proper ocular protection and adult supervision in children will help in a long way in preventing these complications. Prevention of Ocular injuries will save the children from permanent visual disabilities.

\section{Source of Funding: None.}

Conflict of Interest: None.

\section{References}

1. Pattern of Pediatric ocular trauma in India: Saxena R, Sinha R, Purohit A, Dada T, Vajpayee RB, Azad RV. Rajendra Prasad centre for Ophthalmic Sciences, New Delhi, India. Indian J Pediatrics 2002;69(10):863-7.

2. Maurya RP, Srivastava T, Singh VP, CP Mishra, Al-Mujaini A The epidemiology of ocular trauma in Northern India: A teaching hospital study. Oman J Ophthalmol 2019;12(2):78-83.

3. Epidemiology of Childhood Ocular Trauma in a Northeastern Colombian Region. Arch Ophthalmol. 2003;121(10):1439-45.

4. Pattern of pediatric ocular trauma in India. IJO 2002;69(10):862-3.

5. Maurya RP, Singh VP, Singh MK,Mishra CP, Sen PR, Kunwar A. Profile of pediatric ocular trauma at a tertiary eye care center in Northern India. Indian J Clin Exp Ophthalmol 2015;1(2):76-3.

6. Narang S, Gupta V, Simalandhi P, Gupta A, Raj S, Dogra MR. Paediatric open globe injuries. Visual outcome and risk factors for endophthalmitis. Indian J Ophthalmol 2004;52:29-34.

7. C G Thompson Kumar, F A. Bilson, F Martin. The etiology of perforating injuries in children. Br J Ophthalmol 2002;86(8):920-2.

8. Sharma T, Agarwal P, Gopal L, Badrinath SS, Murugesan R. Penetrating ocular trauma in children by "broomstick bows and arrows". Source Vision Research Foundation, Madras, India. Ophthalmic Surg 1994;25(3):175-9.

9. Tariq Farooq Babar, Sanaullah Jan, Loreena Gul, Muhammad Tariq. Pattern of Pediatric Ocular Trauma in Hayatabad Medical Complex, Peshawar. Pak J Med Res 2006;45(1).

10. Megan Brophy, Sara A. Sinclair, MPH, Sarah Grim Hosteler. Pediatric Eye Injury-Related Hospitalizations in the United States. Am J Pediatrics 2006;117(6):e1263-e71.

11. Mohd Alhashki. Retrospective analysis of Pediatric ocular trauma at Price Ali Hospital. Arch Dis Child 1989;64(3):31720.

12. Nelson LB, Wilson TW, Jeffers JB. Eye injuries in childhood: demography, etiology and prevention. Pediatrics 1998;84:438.

13. Krishnan M, Sreenivasan R. Ocular injuries in union territory of Pondicherry-Clinical presentation. Indian J Ophthalmol 1988;36:82-5.

14. Hamid Hosseini, Masoumeh Masoumpour. Clinical and epidemiologic characteristics of severe childhood ocular injuries in south Iran. Middle east. Afr J Ophthalmol 2011;18(2):136-40.

How to cite this article: S. Amudhavadivu, Y. Rogavi, J Gnanaselvan. Ocular trauma in school going children- An analytical study. Indian $J$ Clin Exp Ophthalmol 2019;5(3):398-400. 